\title{
Eye Examination Techniques for Malingering Patients- A Review
}

\author{
Janak Poudel \\ B.Optom, \\ Vittala International Institute of Ophthalmology, India
}

\author{
Premnath Krishnasamy \\ M. Optom, Assistant Professor, \\ Vittala International Institute of Ophthalmology, India
}

\begin{abstract}
Malingering manifest as either imitating an ophthalmic disease, or contradiction of ophthalmic disease. In all cases of imitating or denial of ophthalmic disease there is only one reason i.e. Benefit and advantages. Benefit may be financial or nonfinancial. Sometimes it may be the reason for escape of military service or work, depletion of court penalty, tricky way of getting compensation from insurance companies and unnecessary free medicines or medical equipments. Malingerer does everything to cheat ophthalmologist/optometrist. Commonly it is associated with concurrent diagnosis of depression, anxiety, panic attacks, fibromyalgia and psychiatric disorders.
\end{abstract}

Keywords: Malingering, Simulation, Subjective, Objective, Optokinetic Nystagmus(OKN), Visually Evoked Potential (VEP).

\section{INTRODUCTION}

Ophthalmologist and Optometrist are nowadays facing a problem / complain about a functional visual loss for which they are unable to explain about their condition and it is very difficult to deal with them. When even the most thorough examination and questioning does not divulge the reasonable cause of the visual loss, the optometrist or ophthalmologist may doubt an ocular malingering ${ }^{1-3}$. Malingering manifest as either imitating an ophthalmic disease, or contradiction of ophthalmic disease. In all cases of imitating or denial of ophthalmic disease there is only one reason i.e. Benefit and advantages. Benefit may be financial or nonfinancial. Sometimes it may be the reason for escape of military service or work, depletion of court penalty, tricky way of getting compensation from insurance companies and unnecessary free medicines or medical equipments. Their main motto is to get attraction of sympathy from family members and neighborhood 9-13. Malingerer does everything to cheat ophthalmologist/optometrist. Commonly it is associated with concurrent diagnosis of depression, anxiety, panic attacks, fibromyalgia and psychiatric disorders. To understand the doctors behavior and examination techniques malinger will be very attentive and clever to hide his/her false behaviour.
Patient may assult or shows some misbehavior towards Ophthalmologist/Optometrist if we explain about their false behaviour 15. Although at first, it is very difficult for ophthalmologist/optometrist to distinguish whether the patient would be really ill or whether they are malingering .

Listed important points can be very helpful in doubtful cases:

1. We have to Perform examination as a daily routine work smoothly and quickly. Do not let patient to know about your diagnosis or else patient may be very much attentive towards examination ${ }^{(11,20)}$.

2. Note down all the complaints and symptoms as well as notice the patients behavior while he enters the OPD, posture, mental profile and reactions.

3. It will be better if you examine the patient alone without any relatives or friends .

4. An eye witness may be a doctor with you during examination is necessary in case of future judicial investigations ${ }^{17}$.

* Malingering Triggers;

$>$ Poor medical knowledge

$>$ Low socioeconomic status

$>$ Lack of concern for one's situation

$>$ Mild injury

Psychological events

$>$ Existing health conditions ${ }^{10}$

* Symptoms;

$>$ Light sensitivity

$>$ Ocular discomfort/pain

$>$ Blepharospasm

$>$ Color vision loss

Blurred or decreased vision ${ }^{9}$ 
* Types of MalingeringPatients ${ }^{2}$ :

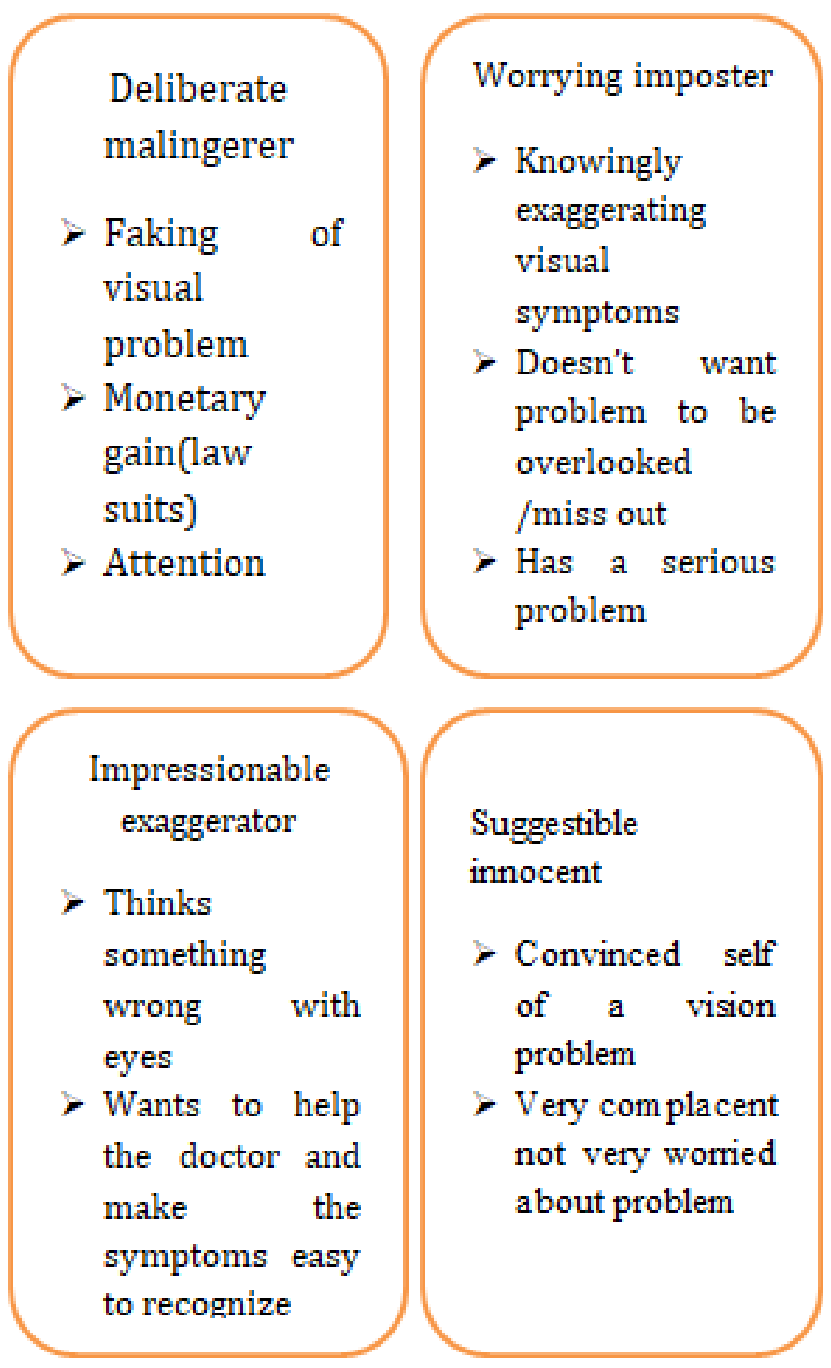

\section{ASSOCIATED DIAGNOSIS}

Diagnosing the malingering patient is much more difficult along with that the associated diagnosis should be determined from the following conditions which produce loss of visual acuity although the anterior segment and fundus appears normal.

1. Amblyopia : Individual may come up with condition that unilateral or bilateral decreased of visual function which may be caused by form vision deprivation or an abnormal binocular interaction that cannot be explained by a disorder of ocular media or visual pathway itself.

2. Cortical blindness: It is characterized by : loss of vision in both eyes, Round, regular and reacting of pupil to light, Anton syndrome, Riddoch phenomenon.

3. Retrobulbar neuritis: -Loss of visual acuity which is frequently about $6 / 60$ but all degrees of defect through to loss of light perception may occur with normal fundus . Afferent pupil defect which indicates optic nerve or retinal disease and VER are diagnostic.
4. Chiasmal tumor: complain of loss of visual acuity but with the normal fundus (before the onset of optic atrophy). Pupil reactions are sluggish to light along with that some visual fields defects may be seen.

5. Anxiety and depression

6. Panic attacks

7. Fibromyalgia

8. Psychiatric disorders in up to $50 \%$

9. Conversion disorder ${ }^{14}$

\section{CLINICAL EXAMINATIONS}

The technique to identify Malingering patients depends on the level of visual loss they claim. But according to the test done like visual acuity, visual field ,Visually evoked potential test etc. claiming malingering is a difficult task. Every subjective and objective tests should be done to diagnose malingering along with the sincere cooperation of subject.

\section{Subjective test for Malingerer:}

\section{Eye contact:}

Eye contact is an important sign to differentiate malingering from ophthalmic disease. It is easy to catch a malingering patient those who assert that they are totally blind by the help of eye contact with examiner ${ }^{3,9,20}$.

\section{Observation:}

Truly blind persons always proceed cautiously and avoid the objects like furniture and dustbins etc. but malingerers knowingly bump into objects ${ }^{3,11,20}$.

\section{Hand looking test:}

Examiner asks the patient to look at their own hand. Truly blind patient moves his hand, looks at it and says I cannot see my hand but I know where is it. But malingerer moves his hand and say I am totally blind I cannot see it. $^{3,11,20}$.

\section{Signature Test:}

Truly blind patients can do these without difficulty as these do not require vision but malingering patients will often not be able to do them, they will just scribble something ${ }^{11,20}$.

\section{Surprise Test:}

Suddenly if examiner makes a face or makes shocking actions, etc. and observes the patients response, a change in the patients look is suggestive of malingering.

\section{Mirror test:}

It is very useful as well as rarely used test. The examiner moves the mirror towards and away from the subject and simultaneously examiner looks at the subjects eye secretly. If the subject moves his eye and look in the mirror, then it denotes that patient is able to see $e^{9,12,20}$. 


\section{Finger to nose test:}

It is an interesting test in which, subject is asked to close his eyes and touch his/her index finger to nose. Malingering patients, acts like they are unable to do it ${ }^{9}$.

\section{Menace test:}

When the examiner move their hand close towards the subject eye immediately, when the patient is sitting in chair comfortably. And if the patient closes his eyes, it denotes that they are normal. Again when the examiner suddenly tries to touch the body part of the subject, and the patient tries to avoid it then it denotes that they can see ${ }^{11,19,20}$.

\section{Pinhole test:}

When the subject is asked to read the letter at distance by keeping a pinhole before good eye and bad eye is kept as it is. During the test if the patient keeps on reading the letter then the examiner slowly place out the pinhole from the trail frame without subject's awareness. If patient is able to read then, let him continue reading till last line ${ }^{15,19}$.

\section{Lens Fogging method:}

This technique involves blurring the good eye with convex lenses while patient views snellen's chart binocularly. Higher plus lenses (+10D) are better than other lenses. Slowly the fogging lens are removed till the acuity increases .The acuity achieved represents the function of supposed bad eye.

\section{Colored lens test:}

Subject's is asked to read the letters with different color on white background with the best corrected visual acuity colored lens. The same color letters is impossible to read with the matching color of lens. If the person can read all the letters, it confines malingering because, normally one can see only red letters through red glass ${ }^{3,15}$.

\section{Prism shift test:}

Prism test is the best subjective test to determine the malingering patients. A normal prism shift occurs in presence of binocular vision. The 4 prism lens is placed in front of alleged bad eye, if there is good vision in that eye a compensatory movement of both eyes towards apex of prism followed by convergence movement of fellow eye back to center occurs ${ }^{12,19}$.

\section{Mojon test:}

Snellens letter of 10 rows having an equal minimum angle of resolution is shown to the patient. If the patient inform that they cannot read the letters then it conforms Malingering ${ }^{28}$.

\section{Duane test:}

It is as same as prism test, where examiner puts $10 \mathrm{PD}$ base up lens on defective eye while subject is reading near chart with both eyes open, and if patient delay to read even a second, it's malingering ${ }^{12}$.

\section{OBJECTIVE TEST FOR MALINGERER}

\section{Optokinetic nystagmus test:}

It is an objective method of visual assessment in uncooperative children as well as adults. In this test, nystagmus is elicited by passing a succession of black and white strips by means of OKN drum. If the patient eye moves along with the movement of the strips then it means patient is able to see ${ }^{11-12}$.

\section{Pupils :}

Totally blind eye has nonreactive pupil to light, only cortical blindness is associated with intact pupillary reactions. So if a patient claims of total blindness with intact pupillary response and no evidence of cortical blindness , suspect malingering. In case of unilateral vision loss, a relative afferent pupillary defect (RAPD) is usually present.

\section{Psychogalvanic test:}

Psychogalvanic test can be determined by the help of slit lamp. In this, patient is made to sit in front of slit lamp and immediately bright light is reflected on his bad eye. If the patient reacts to light by blinking /watering or same facial changes then we can conform that he/she is able to see the light ${ }^{11,20}$.

\section{Pattern visually evoked potentials:}

A normal pVEP in such a case indicates that the visual pathway is normal, at least to the level of the striate and extrastriate cortex. The sVEP for a malingerer or a patient with hysteria usually indicates good acuity even though their Snellen acuity is poor. A poor pVEP result in cases of malingering and hysteria must be viewed with caution. The patient can influence the pVEP results by not fixating the stimulus or blurring (e.g., by over accommodating) the stimulus pattern. Patients should be closely monitored to avoid their influencing the results. The NEP can be recorded if the examiner believes the patient is trying to influence the results. Because the tVEP uses a bright light that stimulates a significant amount of the retina, the tVEP response is not influenced by fixation instability or blur.

\section{LIST OF QUESTIONNAIRES}

* Questions for children:

$>$ Is the child browsing in the optical prior to examination?

$>$ Does the parent think the child has a visual problem, or suspect an ulterior motive?

$>$ Does the parent think the child squinting, covering an eye, sitting close to the television, etc.?

$>$ Is the child performing well in school?

$>$ Did a sibling, friend or parent recently get a new pair of glasses?

\section{* Questions for adults}

$>$ Does the patient seem to have a known motive such as a pending lawsuit, disability, claim etc?

$>$ Did the patient drive to the exam?

$>$ Asking a simple question such as "what time it is" if he or she is wearing a watch, or "what color are my eyes?" 
ISSN No:-2456-2165

Does the problem exist at both distance and near?

\section{* Management.}

This is mostly based on the physician's encouragement to patient reassuring that there is no major problem.

Emotional support for the family, requests for special needs at school.

> Placebo treatment like prescribing low power glasses, various drops, contact lenses etc.

Consistent follow up for frequent no- shows.

\section{CONCLUSION}

Diagnosing the malingering patient is much more difficult. so the subjective as well as objective test should be carried out properly. And those tests mainly help us to confirm about the malingering nature of patient and prove that they are having the normal visual acuity.

Mainly kids just act as a loss of vision or blurring of vision just for the need of spectacle for cosmetic purpose or by their friend circle as well as to avoid their study. So for this good communication should be their between the Ophthalmologist/Optometrist and patient family to know about the nature of case as well as to diagnose the case properly.

\section{REFERENCES}

[1]. Kathol RG, Cox TA, Corbett JJ, Thompson HS. Functional visual loss. Followup of 42 cases. Arch Ophthalmol 1983;101(5):72935

[2]. Thompson HS. Functional visual loss. Am J Ophthalmol1985;100(1):20913

[3]. Incesu AI, Sobaci G. Malingering or simulation in ophthalmology-

[4]. visual acuity.2011;4(5):558-566

[5]. M Fahle, G Mohan, Assessment of visual function in suspected ocular malingering British journal of Ophthalmology, 1989,73,651-654.

[6]. Agatston H. Ocular malingering, Arch Ophthalmol 1944;31:223-31.

[7]. Kramer KK, la Piana FG, Appleton B. Ocular malingering and hysteria. Surv Ophthalmol1979;24:89-96.

[8]. Miller BW. A review of practical test for ocular malingering and hysteria. Surv Ophthalmol 1973;17:241-6.

[9]. Quam K. Ocular malingering. Am Orthopt J 1974;24:73-6.

[10]. Villegas RB, Ilsen PF. Functional vision loss: A diagnosis of exclusion.

[11]. Optometry 2007;10(78):523-533

[12]. Heruti RJ Levy A, Adunski A, Ohry A. conversion motor paralysis disorder: overviewand rehabilitation. Spinal Cord. 2002;40:327-334.

[13]. Sobaci G.[Functional loss in neurophthalmology] rooftalmolojide fonksiyonel kayiplar. In: O'Dwyer PA, Kansu T, Torun N. (Editors) Norooftalmoloji El Kitabi. Ankara, Gunes Kitabevi 2008; pp. 137-145
[14]. Gandhi R, Amula GM. Malingering in Ophthalmology. eMedicine specialties. ophthalmology.unclassified disorders. update sep 2, 2009

[15]. Arnold AC. Nonorganic visual disorders. In: Albert DM, Jacobiec FA (Editors) Principles and Practise of Ophthalmology. Philadelphia, Saunders; 2000; pp 4317-4324.

[16]. Lim SA, Siatkowski RM, Farris BK. Functional visual loss in adults and children patient characteristics, management, and outcomes. Ophthalmology Oct;2005 112(10):1821-1828. [PubMed: 16140382]

[17]. Ledoux-Skivee C, Ledoux A. Simulation et dissimulation en ophtalmologie. Bull Soc Belge Ophthalmol 2004;(291):29-36.

[18]. Scott JA, Egan RA. Prevalence of organic neuroophthalmologic disease in patients with functional visual loss.2003;135(5):670-675

[19]. Sletteberg O, Bertelsen CT, Hovding G. The prognosis of patients with hysterical visual impairment.1989;67(2):159-163.

[20]. Weller M, Wiedemann P. Hysterical symptoms in ophthalmology. Doc Ophthalmol 1989;73(1):1-33.

[21]. Singhal NC. Hysterical blindness versus malingering. Indian J Ophthalmol 1972;20(4):173-178

[22]. Beatty S. Nonorganic visual loss. Postgrad Med J 1999; 75(882):201-207.

[23]. Nuzzi R, Chiado Piat L. Outpatient tests for visual acuity evaluation in malingerers: A review and personal experience.1994;26 (5): 175-82.

[24]. Baserer T.[Functional visual loss-review] Fonksiyonel(organik olmayan) gorme kayiplariderleme.2008;38(5):438-442.

[25]. Shindler KS, Galetta SL, Volpe NJ. Functional visual loss. Curr Treat Options Neurol 2004;6(1):67-73.

[26]. Graf MH, Roesen J. Ocular malingering. A surprising visual acuity test. Arch Ophthalmol 2002;120(9):756760.

[27]. Graf MH. Information from false statements concerning visual acuity and visual field in cases of psychogenic visual impairment Grafs Arch Clinc Exp Ophthalmol 1999;237(1):16-20.

[28]. Slavin ML The prism dissociation test in detecting unilateral functional visual loss.1990;10(2):127-130.

[29]. Weinstein GW, Odom JV, Cavender S. Visually evoked potentials and electroretinography in neurologic evaluation.1991;9(1):225-242.

[30]. Mojon DS, Flueckiger P. A new optotype chart for detection of nonorganic visual loss2002;109(4):810815 